\title{
Dexmedetomidine Use during Strabismus Surgery in Agitated Children
}

\author{
Ayse Mizrak $^{\mathrm{a}} \quad$ Ibrahim Erbagci $^{\mathrm{b}}$ Tulin Arici $^{\mathrm{a}}$ Neslihan Avci ${ }^{\mathrm{a}}$ \\ Suleyman Ganidagli ${ }^{\mathrm{a}} \quad$ Unsal Oner $^{\mathrm{a}}$ \\ Departments of a Anesthesiology and Reanimation and ${ }^{b}$ Ophthalmology, Gaziantep University School of Medicine, \\ Gaziantep, Turkey
}

\author{
Key Words \\ Ketamine $\cdot$ Dexmedetomidine $\cdot$ Strabismus surgery $•$ \\ Agitated patient
}

\begin{abstract}
Objective: We aimed to investigate the effects of dexmedetomidine premedication before intravenous infusion of ketamine in agitated children undergoing strabismus surgery. Subjects and Methods: We enrolled 60 agitated pediatric patients, aged 4.5-11 years. The patients were randomly allocated to one of two anesthesia regimens. Group D patients were premedicated with a single dose of intravenous dexmedetomidine $0.5 \mu \mathrm{g} / \mathrm{kg}$ whereas group $\mathrm{P}$ patients received a placebo. Patients in both groups were administered intravenous ketamine $1 \mathrm{mg} / \mathrm{kg}$ i.v. over $1 \mathrm{~min}$ followed by a continuous infusion of ketamine $1-3 \mathrm{mg} / \mathrm{kg} / \mathrm{h}$ i.v. $(\mathrm{n}=30)$. Patients were intubated after receiving fentanyl $1 \mu \mathrm{g} / \mathrm{kg}$ and rocuronium bromide $0.5 \mathrm{mg} / \mathrm{kg}$. Results: 21 (70\%) patients in group D did not show the oculocardiac reflex (OCR) versus 7 (23\%) in group $P(p=0.0006)$. The preoperative and postoperative agitation scores ( $p=0.0001$ and $p=0.03$, respectively), the score on the Faces Pain Scale during awakening [3.0 (interquartile range, IQR 2.0-4.0) in group D and 0.0 (IQR 1.0-2.25) in group $P](p=0.001)$ and at the 60th postoperative minute [IQR 2.0 (1.5-3.0) in group D and 2.0 (IQR 1.5-3.0) in group P] ( $p=$ $0.004)$, sore throat $(26.6 \%$ in group $D$ and $60 \%$ in group $P)$ $(p=0.01)$ and analgesic requirement (20\% in group D and $53 \%$ in group $P)(p=0.01)$ in group $P$ were significantly higher than
\end{abstract}

in group D. The Ramsay Sedation Score (RSS) in group D was significantly higher than in group $\mathrm{P}$ during awakening [2.0 $(2.0-2.0)$ in group D and $4.5(4.0-5.0)$ in group $P](p=0.0001)$. Conclusion: Dexmedetomidine premedication followed by intravenous infusion of ketamine was effective in decreasing OCR, agitation, pain, analgesic requirement in agitated children undergoing strabismus surgery.

Copyright $\odot 2011$ S. Karger AG, Basel

\section{Introduction}

Strabismus surgery is one of the most common eye operations in children and it may be associated with significant postoperative pain [1] caused by the conjunctiva. Both pain and vomiting cause distress, anxiety and agitation in children [2]. As anxiety can increase distress and may cause difficulties in controlling postoperative pain [3], it is important to provide safe and effective analgesia.

The oculocardiac reflex (OCR) is a major complication of pediatric strabismus surgery when the heart rate (HR) drops to $20 \%$ of the resting rate. The incidence of the OCR during strabismus surgery has been variously reported between 14 and 90\%, depending on the premedication, anesthetic agent and the definition of OCR [4, 5]. A variety of methods, such as prevention of hypoxemia and hypercapnia, premedication using atropine or glycopyrrolate, and adequate anesthetic depth, have failed to prevent the OCR [4].

\section{KARGER}

Fax +4161306 1234

E-Mail karger@karger.ch

www.karger.com
(C) 2011 S. Karger AG, Basel

1011-7571/11/0205-0427\$38.00/0

Accessible online at:

www.karger.com/mpp
Dr. Ayse Mizrak

Gaziantep University Medical Faculty

Department of Anesthesiology and Reanimation

TR-27310 Sahinbey, Gaziantep (Turkey)

Tel.+90 5337181 025, E-Mail aysemizrak@ hotmail.com 
Ketamine anesthesia is associated with the least hemodynamic changes during strabismus surgery in pediatric patients [6], probably due to its various reaction mechanisms, which include the N-methyl-D-aspartate receptor antagonist properties $[7,8]$, and intrinsic analgesic and amnestic properties that protect airway reflexes $[9,10]$. In subanesthetic doses, ketamine has an analgesic effect [8]. Furthermore, low-dose ketamine increases thalamic sensory output and arousal [11] and is characterized by a relatively rapid onset of action and a short duration of action. Ketamine anesthesia may counteract vagal stimulation and protect against parasympathetic activation induced by the OCR in patients who are more prone to developing OCR. Therefore, the administration of intravenous ketamine appears to be a safe and useful technique for monitoring anesthesia care in the ambulatory setting.

Dexmedetomidine is a selective $\alpha_{2}$-adrenergic agonist that exhibits high specificity for the $\alpha_{2}$-receptor which inhibits adenyl-cyclase activity [12] and has sedative, analgesic and anxiolytic properties. Dexmedetomidine may decrease the use of opiods and other sedatives since it potentiates their effects $[12,13]$. Candiotti et al. [13] reported that less fentanyl was required for sedation with dexmedetomidine ( 84.8 vs. $144.4 \mu \mathrm{g}$ for the dexmedetomidine and placebo groups, respectively) compared with midazolam (placebo) for all surgical subtypes. Combination of ketamine and dexmedetomidine has several advantages: the decreased dosages of both sedative agents needed for clinical sedation decreased hemodynamic side effects [14]; intravenous injection enables quicker recovery [15] and causes less air pollution in the operating room than inhaled anesthetics [16]. Mahmoud et al. [17] reported that addition of dexmedetomidine decreased the dose of ketamine and thereby its related side effects. Therefore, we aimed to investigate the effects of dexmedetomidine premedication before intravenous infusion of ketamine in agitated children undergoing strabismus surgery.

\section{Subjects and Methods}

This study was performed from September to November 2009 in accordance with the most recent version of the Helsinki Declaration and approved by the Medical Faculty Ethical Committee of Gaziantep University. After approval from the institutional review board, written informed consent was obtained from the patients' families. This study was conducted in the day-surgery ward of the Anesthesiology Department. The study group comprised 60 agitated patients with an American Society of Anesthesiologists (ASA) physical status I.
Exclusion criteria: patients with ASA physical status $>$ I, those who were younger than 4 years or older than 11 years, those who had seizures or psychoses, allergy to study drugs, hypertension, psychiatric disorders, cardiovascular (ischemic heart disease, heart block, arrhythmia) and clotting disorders, or those whose families did not consent to the study. Each patient's family was informed of the objectives of the study. None of the patients was premedicated with another drug. Patients were randomized into the two pretreatment groups using a computer-generated random number table. One group (group D, $\mathrm{n}=30$ ) received dexmedetomidine (Precedex ${ }^{\circledR}$, Abbott, $200 \mu \mathrm{g} / 2 \mathrm{ml}$, Istanbul, Turkey) $0.5 \mu \mathrm{g} / \mathrm{kg}$; the other group (group $\mathrm{P}, \mathrm{n}=30$ ) received a placebo. The premedication drugs were prepared with isotonic saline solution in unlabeled $20-\mathrm{ml}$ syringes. After the patients had been taken to the surgical room, standard monitors, i.e. electrocardiography, mean arterial blood pressure (MAP), heart rate (HR), $\mathrm{EtCO}_{2}$ and pulse oximetry were used. A 22-gauge cannula was inserted into a vein in the dorsum of the hand, and saline was infused at a rate of $3 \mathrm{ml} / \mathrm{kg} / \mathrm{h}$. After preoxygenation, the study solutions were given intravenously over a 10 -min period by an anesthesiologist who was blinded to the study. Ketamine $1 \mathrm{mg} / \mathrm{kg}$ was given intravenously over a 60 -second period by the same anesthesiologist. After administering fentanyl $1 \mu \mathrm{g} / \mathrm{kg}$ (Fentanyl citrate, B. Braun Melsungen AG, Berlin, Germany, 5 ampoules, $0.05 \mathrm{mg} / \mathrm{ml}$ ) and rocuronium bromide $0.5 \mathrm{mg} / \mathrm{kg}$ i.v. (Esmeron, Organon, Oss, The Netherlands, $10 \mathrm{mg} / \mathrm{ml}$ ), the patients were intubated. Anesthesia was maintained with continuous intravenous infusion of ketamine with $50 \%$ oxygen and $50 \%$ air at 6 liters $/ \mathrm{min}$. Patients in groups $\mathrm{P}$ and $\mathrm{D}$ were infused ketamine hydrochloride (Pfizer, flacon, $50 \mathrm{mg} / \mathrm{ml}, \operatorname{Ketalar}^{\circledR}$, Ortakoy, Istanbul) at a varied rate of 1-2 $\mathrm{mg} / \mathrm{kg} / \mathrm{h}$ i.v., providing a satisfactory anesthesia depth. All procedures were performed by the same surgeon. Atropine was available before traction of the extraocular muscle was begun. During the traction, the minimal HR was recorded. If the HR decreased from the basal HR by $20 \%$, the anesthesiologist asked the surgeon to release the extraocular muscle. If bradycadia did not improve, atropine $0.01 \mathrm{mg} / \mathrm{kg}$ was administered intravenously. The hemodynamics were recorded at the following time points: intubation, incision, operation, extubation and postextubation.

Recovery time was the time from the cessation of anesthetic infusion to verbal communication. Duration of surgery was the time from incision to complete hemostasis. Duration of mental orientation was the time from the end of intravenous anesthetic administration to obtaining a correct response to two orientation questions (Where are you? and Who am I?). Intravenous anesthetics were stopped 5 min before ending the operation and extubation was performed. The number of OCR and the incidence of nonexistence of OCRs were recorded during surgery. The consumption (mg) of ketamine during surgery was recorded as well. Postoperative nausea and vomiting $(\mathrm{PONV})$ were evaluated via the Numeric Rank Score (NRS): nausea $=0$; vomiting and nausea once $=1$; vomiting and nausea twice or more times $=2$, based on a previous study [1]. The evaluation of postoperative pain was performed using the Faces Pain Scale (FPS) [18]: 0 (no pain) to 10 (severe pain) metric evaluation [19]. The Ramsay Sedation Score (RSS) was recorded on a numerical scale: anxiety and completely awake $=1$; completely awake $=2$; awake but drowsy $=3$; asleep but responsive to verbal commands $=4$; asleep but responsive to tactile stimulus $=5$; and asleep and not responsive to any stimulus = 6 . The preoperative (before premedication) and postoperative ag- 
itation (during awakening and during the first hour in the postoperative period were evaluated using an emergence agitation (behavior score) score (sleeping $=1$, awake and calm $=2$, irritable and crying $=3$, inconsolable crying $=4$, severe restlessness and disorientation purposelessly wanting to get out of the bed, wanting to stand in the bed, shouting, crying, or mumbling loudly = 5) [20]. As assessment of pain in younger children is difficult because of their limited understanding and verbal abilities, the evaluations of the FPS, RSS and agitation score were performed with the help of the children's parents during awakening. At the end of the operation, the satisfaction score of the surgeon was assessed according to the following numeric scale: score $1=$ unsuccessful (continuous ocular motion bothering the surgeon); score $2=$ moderate (due to a small motion of ocular globe back, which required supplemental anesthetics); score 3 = good (minor complaint without any need for supplemental anesthetics); score $4=$ excellent (no complaint from surgeon).

Furthermore, all the evaluations and records were performed by a blinded observer different from the person who performed the study. In addition, patients were observed for intraoperative hypertension (defined as MAP 20\% higher than the baseline value, $\mathrm{mm} \mathrm{Hg}$ ), hypotension (MAP 20\% lower than the baseline value, $\mathrm{mm} \mathrm{Hg}$ ), tachycardia (defined as HR 20\% higher than the baseline value, beat $\left.\cdot \mathrm{min}^{-1}\right)$, postoperative nausea, vomiting, coughing, straining, laryngospasm, hypoxemia (defined as $\mathrm{SpO}_{2} \leq 90 \%$ ) and sore throat. The bradycardia was treated with $0.01 \mathrm{mg} / \mathrm{kg}$ of atropine; nausea was treated with trimetobenzamid $\mathrm{HCl}$ (Emedur ${ }^{\circledR}, 150 \mathrm{mg}$, Salofi Sinthelabo, ampoule). A nonopioid analgesic (paracetamol) was given to patients who had FPS $>3$ after the operation. Patients were discharged from the hospital within the first $4 \mathrm{~h}$ after surgery if their motor-mental functions had returned completely, if they had no bleeding, nausea or vomiting and if they could be fed.

\section{Statistical Analysis}

The results of the study were evaluated using the SPSS statistical analysis package (Statistical Package for Social Sciences Release 15.0 for Windows). Age, weight, recovery time, HR, MAP, consumptions of anesthetics and antiemetics, and anesthesia times were compared among the groups using an independentsample t test. Statistical analyses included Fisher's exact test for nominal data, the Mann-Whitney U test or the Wilcoxon W test for nonparametric or ordinal data and Student's t test for continuous data. Nonparametric or ordinal data are presented as median (25-75\% interquartile range, IQR), and continuous data are presented as means \pm standard deviation. $p$ values $<0.05$ were considered significant.

\section{Results}

The demographic characteristics (age, body mass index and gender), recovery times, duration of surgery and mental orientation, and the consumption of anesthetics were similar in both groups (table 1). The incidence of patients with agitation scores $<4$ during the first postoperative hour was similar in groups D and P (group D,
Table 1. Demographic data, recovery times, duration of surgery and mental orientation, agitation score and consumption of anesthetics

\begin{tabular}{lccc}
\hline & $\begin{array}{c}\text { Group D } \\
(\mathrm{n}=30)\end{array}$ & $\begin{array}{c}\text { Group P } \\
(\mathrm{n}=30)\end{array}$ & $\mathrm{p}$ \\
\hline Age, years & $8.5 \pm 2.6$ & $8.6 \pm 2.8$ & 0.7 \\
Weight, kg & $28.6 \pm 10.7$ & $29.5 \pm 7.8$ & 0.2 \\
Body mass index, kg/m ${ }^{2}$ & $17.0 \pm 5.6$ & $16.7 \pm 1.2$ & 0.2 \\
Gender, M/F & $15 / 15$ & $13 / 17$ & 1.0 \\
Recovery times, min & $7.8 \pm 3.7$ & $7.5 \pm 4.1$ & 0.8 \\
Duration of surgery, min & $47.6 \pm 14.3$ & $46.6 \pm 17.0$ & 0.2 \\
Duration to mental orientation, min & $37.2 \pm 11.5$ & $35.9 \pm 7.0$ & 0.6 \\
Patients with agitation score $<4$ & & & \\
$\quad$ during the 1st postoperative hour, $\mathrm{n}$ & $8(26 \%)^{*}$ & $4(13 \%)$ & 0.3 \\
Consumption of anesthetics, mg & $54.1 \pm 30.9$ & $54.5 \pm 23.6$ & 0.5 \\
\hline
\end{tabular}

Data are presented as means \pm SD or $\mathrm{n}(\%)$

${ }^{*} \mathrm{p}<0.05$ compared with group P.

$26 \%, 8$ patients and group $P, 13 \%, 4$ patients; $p=0.3)($ table 1). The incidence of nonexistence of OCR was significantly higher in those receiving dexmedetomidine compared with placebo (group D, 70\%, 21 patients and group $\mathrm{P}, 23 \%, 8$ patients; $\mathrm{p}=0.0006$ ). Atropine was required in $6 \%$ in group $\mathrm{D}$ ( 2 patients) versus $23 \%$ (8 patients) in group $\mathrm{P}(\mathrm{p}=0.15)$.

The OCR was not observed in $21(70 \%)$ patients in group D and in $7(23 \%)$ in group $\mathrm{P}(\mathrm{p}=0.0006)$. Preoperative and postoperative agitation score $(\mathrm{p}=0.0001$ and $\mathrm{p}=0.03$, respectively), FPS during awakening [3.0 (2.04.0 ) in group $\mathrm{D}$ and 0.0 (IQR 1.0-2.25) in group $\mathrm{P}](\mathrm{p}=$ $0.001)$ and at the 60th postoperative minute [IQR 2.0 (1.53.0) in group D and 2.0 (IQR 1.5-3.0) in group P] ( $\mathrm{p}=$ $0.004)$, sore throat $(26.6 \%$ in group $\mathrm{D}$ and $160 \%$ in group $\mathrm{P})(\mathrm{p}=0.01)$ and analgesic requirement $(20 \%$ in group $\mathrm{D}$ and $153 \%$ in group $P)(p=0.01)$ were significantly higher in group $\mathrm{P}$ than in group D. The RSS was significantly higher in group $\mathrm{D}$ than in group $\mathrm{P}$ during awakening [2.0 (IQR 2.0-2.0) in group D and 4.5 (IQR 4.0-5.0) in group $\mathrm{P}](\mathrm{p}=0.0001)$. The HR of the patients in group $\mathrm{P}$ was significantly higher than that in group D during the intubation, incision, extubation, and postextubation periods (fig. 1) $(\mathrm{p}<0.05)$.

RSS, NRS and the surgeon's satisfaction score during the procedure were similar in the two groups (table 2). Seven patients in group D (23\%) and 2 patients in group $\mathrm{P}(6 \%)$ received atropine $0.01 \mathrm{mg} / \mathrm{kg}$ for persistent bradycardia $(\mathrm{p}=0.1)$. MAP was similar in the two groups (fig. 2). Three patients in group D (13\%) and 8 patients in group P received paracetamol $500 \mathrm{mg}$ i.v. for sore throat [the total number was 8 (26.6\%) in group D and $18(60 \%)$ 


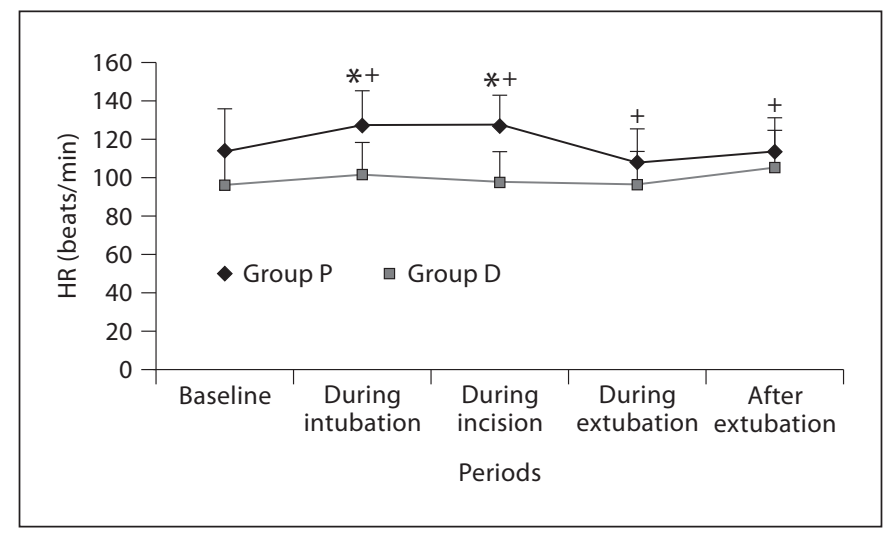

Fig. 1. Comparison of the HR of the patients in the two groups $(\mathrm{n}=30) .{ }^{*} \mathrm{p}<0.05$ when compared with group $\mathrm{D} ;{ }^{+} \mathrm{p}<0.05$ when compared with baseline values.

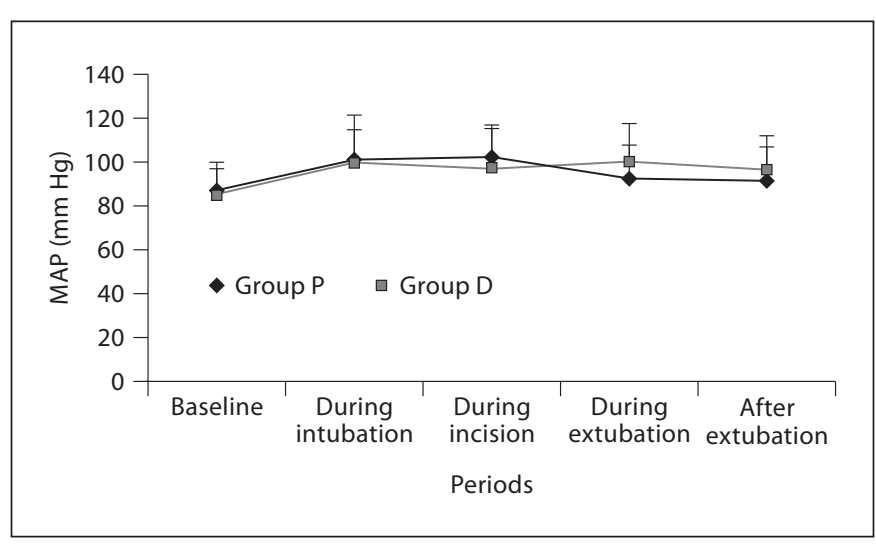

Fig. 2. Comparison of the MAP of the patients in the two groups $(\mathrm{n}=30)(\mathrm{p}>0.05)$.

Table 2. Oculocardiac reflex, atropine requirement, agitation score, Faces Pain Scale, Ramsay sedation score, NRS, sore throat, analgesic requirement and satisfaction score

\begin{tabular}{llll}
\hline & Group D $(\mathrm{n}=30)$ & Group P (n=30) & $\mathrm{p}$ \\
\hline Nonexistence of the OCR, \% & $70 ; 1.0(0.75-3.0)^{*}$ & $23 ; 0.0(0.0-1.0)$ & 0.0006 \\
Atropine requirement, $\mathrm{n}$ & $2(6 \%)^{*}$ & $7(23 \%)$ & 0.1 \\
Preoperative agitation score & $5.0(4.0-6.0)^{*}$ & $5.0(4.0-7.0)$ & 0.0001 \\
Postoperative agitation score during awakening & $3.0(3.0-4.0)^{* * *}$ & $3.0(2.0-3.0)^{* *}$ & 0.03 \\
FPS during awakening & $3.0(2.0-4.0)^{*}$ & $0.0(1.0-2.25)$ & 0.001 \\
FPS at the 60th postoperative minute & $2.0(1.5-3.0)^{* * *}$ & $0.0(0.0-2.0)^{* *}$ & 0.004 \\
RSS during awakening & $2.0(2.0-2.0)^{*}$ & $4.5(4.0-5.0)$ & 0.0001 \\
RSS at the 60th postoperative minute & $2.0(2.0-2.0)$ & $2.0(2.0-3.0)$ & 0.1 \\
Postoperative NRS & $0.0(0.0-0.0)$ & $0.0(0.0-0.0)$ & 0.1 \\
Postoperative sore throat, \% & $26.6^{*}$ & 60 & 0.01 \\
Analgesic requirement, \% & 20 & 53 & 0.01 \\
Surgeon's satisfaction score during the procedure & $1.0(1.0-2.0)$ & $1.0(1.0-2.0)$ & 0.1 \\
\hline
\end{tabular}

Data are presented as medians and $25-75 \%$ IQR (in parentheses) or percentages.

${ }^{*} \mathrm{p}<$ group D compared with group $\mathrm{P} ;{ }^{* *} \mathrm{p}<$ the preoperative values compared with the postoperative values.

in group P] $(p=0.01)$ when FPS $>3$. No patient experienced awareness, recall, excessive salivation, delirium or hallucinations.

In this study, pain stimuli did not differ as a function of surgical procedures, duration of surgery or the number of muscles operated on by the same surgeon.

\section{Discussion}

The combination of dexmedetomidine premedication and intravenous infusion of ketamine decreased the incidence of OCR. In addition, this combination decreased pre- and postoperative agitation, postoperative pain and analgesic requirement versus only intravenous infusion of ketamine. Therefore, there was a trend for less rescue atropine (6 vs. 23\%). Low- and single-dose dexmedetomidine may have limited the tendency to OCR during ketamine anesthesia [12]. There are some undesired effects of the surgery like postoperative pain, anxiety, agitation [21], PONV and OCR [22, 23]. The $0.5 \mu \mathrm{g} / \mathrm{kg}$ of dexmedetomidine given over $10 \mathrm{~min}$ in this study did not produce any clinically major adverse effects of $\alpha_{2}$-agonists such as hypotension and bradycardia [24].

Painful procedures necessary for the care of children are increasing [2]. Excessive pain can significantly length- 
en the postoperative stay. Especially the pain score during awakening affects the patient's agitation score. This adverse effect has a direct negative effect on patient satisfaction [21]. Although all patients in both groups were agitated, the main significant difference between the groups was the preoperative agitation grade, which contributes to less OCR. In this study, FPS during awakening and at $60 \mathrm{~min}$ after surgery, postoperative sore throat due to intubation and total analgesic requirement in group $\mathrm{P}$ were significantly higher than in group $\mathrm{D}$. When given alone, dexmedetomidine has been shown not to be effective in acute, painful, invasive procedures in either pediatric or adult populations $[25,26]$, hence the need for administering it with ketamine. Ketamine is a potent anesthetic with distinct analgesic activity. Dexmedetomidine also induces sedation and analgesia, reduces anesthetic requirements, and improves patients' satisfaction and agitation [27]. Therefore, dexmedetomidine may also be a suitable adjunct to ketamine anesthesia.

The incidence of patients with agitation scores $<4$ during the 1-hour postoperative period was significantly higher in group $\mathrm{D}$ than in group $\mathrm{P}$. The preoperative and postoperative agitation scores during awakening in group $\mathrm{P}$ were significantly higher than in group D. In addition, the postoperative agitation and FPS scores were significantly lower than the preoperative values in group D. The analgesic requirements in group $\mathrm{P}$ were significantly higher than in group D. The RSS in group D was significantly higher than in group $\mathrm{P}$ during awakening. The combined analgesic, sedative and anxiolytic effects of both drugs could be effective in attenuating the pain, anxiety and agitation. Thereby, ketamine infusion in conjunction with low-dose dexmedetomidine could decrease the analgesic requirement of children by increasing the sedation, decreasing the pain and thus agitation [12]. Tobias [20] reported that there is growing interest in the use of dexmedetomidine in the pediatric population in various clinical conditions, including mechanical ventilation and prevention of emergence agitation. Similarly, Tosun et al. [14] reported that because the hemodynamic effects of these agents may offset one another, a combination of ketamine and dexmedetomidine makes sense from a pharmacologic point of view. After the initial bolus of dexmedetomidine and ketamine, we observed only minimal changes in HR and blood pressure. As the increases in HR in group P disappeared in a few minutes, no patient required any treatment. Ibacache et al. [28] observed significantly decreased postoperative agitation and a stable hemodynamic condition at a $0.3 \mu \mathrm{g} / \mathrm{kg}$ bolus dose. Similarly, the incidence of agitation decreased and the hemodynamics were stable at a higher dose $(0.5 \mu \mathrm{g} /$ $\mathrm{kg}$ ) in our study.

In addition, the response to laryngoscopy and endotracheal intubation was significantly attenuated by a single dose of dexmedetomidine via a reduction in norepinephrine turnover and a decrease in central sympathetic outflow [27]. However, higher doses of dexmedetomidine are associated with an additional reduction in arterial pressure and HR [29]. In addition, ketamine may have prevented the bradycardia and hypotension that have been reported with the use of dexmedetomidine [17]. Contrary to the present study, Vainio et al. [30] suggested that, as dexmedetomidine increased intra- and postoperative bradycardia, an anticholinergic drug should be given routinely before induction with ketamine if dexmedetomidine is used. The use of a single and low dose of dexmedetomidine may have been the main result of the current study. Although premedication with dexmedetomidine is effective in attenuating the OCR during ketamine anesthesia, because of the risk of bradycardia, routine use of an anticholinergic drug may be considered.

Yoshikawa and Murai [31] reported that although ketamine was suitable for pediatric use, especially for ophthalmic operations, nystagmus may be considered an undesirable effect of the drug during surgery. In the present study, the surgeon did not complain of this side effect at all. This result may be ascribed to the deep and satisfactory anesthesia. In addition, problems such as alterations in state of mood, unpleasant dreams and even delirium have only been observed in few, special circumstances and high-risk patients $[32,33]$; none of our patients reported awareness, recall, salivation, delirium or hallucinations.

More extensive randomized studies should be performed to help establish the effects of dexmedetomidine premedication before intravenous infusion of ketamine to decrease OCR in agitated children undergoing strabismus surgery. The limitation of our study is the low number of subjects.

\section{Conclusion}

The combination of dexmedetomidine and ketamine as an intravenous hypnotic anesthetic agent provided a safe and effective anesthesia with a decreased incidence of OCR, agitation, pain and analgesic requirement in agitated children undergoing strabismus surgery. 


\section{References}

1 Shende D, Das K: Comparative effects of intravenous ketorolac and pethidine on perioperative analgesia and postoperative nausea and vomiting (PONV) for paediatric strabismus surgery. Acta Anaesthesiol Scand 1999;43:265-269.

-2 Zeltzer L, Kellerman J, Ellenberg L, Dash J, Rigler D: Psychologic effects of illness in adolescence. II. Impact of illness in adolescents - crucial issues and coping styles. J Pediatr 1980;97:132-138.

-3 Gil KM, Ginsberg B, Muir M, Sykes D, Williams DA: Patient-controlled analgesia in postoperative pain: the relation of psychological factors to pain and analgesic use. Clin J Pain 1990;6:137-142.

4 Rusch D, Happe W, Wulf H: Postoperative nausea and vomiting following strabismus surgery in children. Inhalation anesthesia with sevoflurane-nitrous oxide in comparison with intravenous anesthesia with propofol-remifentanil (in German). Anaesthesist 1999;48:80-88.

5 Choi SR, Park SW, Lee JH, Lee SC, Chung CJ: Effect of different anesthetic agents on oculocardiac reflex in pediatric strabismus surgery. J Anesth 2009;23:489-493.

-6 Chhabra A, Pandey R, Khandelwal M, Subramaniam R, Gupta S: Anesthetic techniques and postoperative emesis in pediatric strabismus surgery. Reg Anesth Pain Med 2005;30:43-47.

-7 Krystal JH, Karper LP, Seibyl JP, Freeman GK, Delaney R, Bremner JD, Heninger GR, Bowers MB, Jr, Charney DS: Subanesthetic effects of the noncompetitive NMDA antagonist, ketamine, in humans. Psychotomimetic, perceptual, cognitive, and neuroendocrine responses. Arch Gen Psychiatry 1994;51:199-214.

8 Suzuki M, Tsueda K, Lansing PS, Tolan MM, Fuhrman TM, Ignacio CI, Sheppard RA: Small-dose ketamine enhances morphineinduced analgesia after outpatient surgery. Anesth Analg 1999;89:98-103.

$\checkmark$ White PF, Way WL, Trevor AJ: Ketamine its pharmacology and therapeutic uses. Anesthesiology 1982;56:119-136.

10 Green SM, Johnson NE: Ketamine sedation for pediatric procedures. 2. Review and implications. Ann Emerg Med 1990;19:10331046.
11 Carlsson M, Carlsson A: Schizophrenia: a subcortical neurotransmitter imbalance syndrome? Schizophr Bull 1990;16:425-432.

12 Cortinez LI, Hsu YW, Sum-Ping ST, Young C, Keifer JC, Macleod D, Robertson KM, Wright DR, Moretti EW, Somma J: Dexmedetomidine pharmacodynamics. II. Crossover comparison of the analgesic effect of dexmedetomidine and remifentanil in healthy volunteers. Anesthesiology 2004; 101:1077-1083

13 Candiotti KA, Bergese SD, Bokesch PM, Feldman MA, Wisemandle W, Bekker AY: Monitored anesthesia care with dexmedetomidine: a prospective, randomized, double-blind, multicenter trial. Anesth Analg 2010;110:47-56.

14 Tosun Z, Akin A, Guler G, Esmaoglu A, Boyaci A: Dexmedetomidine-ketamine and propofol-ketamine combinations for anesthesia in spontaneously breathing pediatric patients undergoing cardiac catheterization. J Cardiothorac Vasc Anesth 2006;20:515519.

15 Glaisyer HR, Sury MR: Recovery after anesthesia for short pediatric oncology procedures: propofol and remifentanil compared with propofol, nitrous oxide, and sevoflurane. Anesth Analg 2005;100:959-963.

16 Eyres R: Update on TIVA. Paediatr Anaesth 2004;14:374-379.

17 Mahmoud M, Tyler T, Sadhasivam S: Dexmedetomidine and ketamine for large anterior mediastinal mass biopsy. Paediatr Anaesth 2008;18:1011-1013.

18 Nilsson S, Kokinsky E, Nilsson U, Sidenvall B, Enskar K: School-aged children's experiences of postoperative music medicine on pain, distress, and anxiety. Paediatr Anaesth 2009;19:1184-1190.

19 Carollo DS, Nossaman BD, Ramadhyani U: Dexmedetomidine: a review of clinical applications. Curr Opin Anaesthesiol 2008;21: 457-461.

20 Tobias JD: Dexmedetomidine: applications in pediatric critical care and pediatric anesthesiology. Pediatr Crit Care Med 2007;8: $115-131$.

21 Meeks GR, Waller GA, Meydrech EF, Flautt $\mathrm{FH}$, Jr: Unscheduled hospital admission following ambulatory gynecologic surgery. Obstet Gynecol 1992;80:446-450.
22 Stump M, Arnold RW: Iris color alone does not predict susceptibility to the oculocardiac reflex in strabismus surgery. Binocul Vis Strabismus Q 1999;14:111-116.

23 Lerman J, Eustis S, Smith DR: Effect of droperidol pretreatment on postanesthetic vomiting in children undergoing strabismus surgery. Anesthesiology 1986;65:322-325.

24 Gertler R, Brown HC, Mitchell DH, Silvius EN: Dexmedetomidine: a novel sedative-analgesic agent. Proc (Bayl Univ Med Cent) 2001;14:13-21.

25 Tobias JD, Berkenbosch JW: Initial experience with dexmedetomidine in paediatricaged patients. Paediatr Anaesth 2002;12: 171-175.

-26 Alhashemi JA: Dexmedetomidine vs midazolam for monitored anaesthesia care during cataract surgery. Br J Anaesth 2006;96:722726.

27 Maze M, Tranquilli W: Alpha-2 adrenoceptor agonists: defining the role in clinical anesthesia. Anesthesiology 1991;74:581-605.

28 Ibacache ME, Munoz HR, Brandes V, Morales AL: Single-dose dexmedetomidine reduces agitation after sevoflurane anesthesia in children. Anesth Analg 2004;98:60-63, table of contents

-29 Virkkila M, Ali-Melkkila T, Kanto J, Turunen J, Scheinin H: Dexmedetomidine as intramuscular premedication in outpatient cataract surgery. A placebo-controlled doseranging study. Anaesthesia 1993;48:482487.

30 Vainio OM, Bloor BC, Kim C: Cardiovascular effects of a ketamine-medetomidine combination that produces deep sedation in Yucatan mini swine. Lab Anim Sci 1992;42: 582-588.

31 Yoshikawa K, Murai Y: The effect of ketamine on intraocular pressure in children. Anesth Analg 1971;50:199-202.

32 Chodoff P: Evidence for central adrenergic action of ketamine: report of a case. Anesth Analg 1972;51:247-250.

33 Salt PJ, Barnes PK, Beswick FJ: Inhibition of neuronal and extraneuronal uptake of noradrenaline by ketamine in the isolated perfused rat heart. Br J Anaesth 1979;51:835838. 